\title{
THE THEORY OF ISLAND BIOGEOGRAPHY ON THE HAWAIKI ARCHIPELAGO
}

\author{
BY \\ $\mathrm{KHOI} \mathrm{DINH}$
}

A thesis submitted to the Victoria University of Wellington in fulfilment of the requirements for the degree of Master of Science in Ecology and Biodiversity

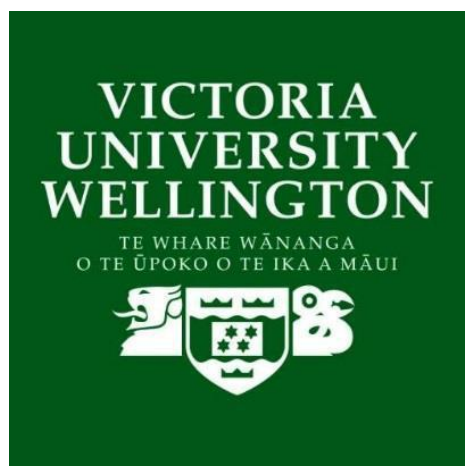

Victoria University of Wellington

2016 


\section{Abstract}

This thesis addresses MacArthur and Wilson's Theory of Island Biogeography (1967) on a set of islands around the north-east coast of the North Island of New Zealand. The flora species lists from these islands were obtained from both published and unpublished island surveys whilst Geographical Information Systems (GIS) techniques were utilised in order to calculate the physical geography of islands.

These islands were an ideal study site for such research because they display natural gradients in both physical geography as well as native and exotic species richness. The literature on the Theory of Island Biogeography has yet to comprehensively understand the differences between the patterns of exotic richness and native richness. Furthermore, the importance of studies on exotics species is increasingly relevant given the negative effect they have had on native communities worldwide.

The results of my research illustrated that there were similar speciesarea and species-isolation relationships between exotic and native species. These two relationships were also consistent with what is expected under classical island biogeography principles. Interestingly however, I found that distance from the mainland had a stronger negative effect on exotics species. There were a significantly lower proportion of exotics with increasing isolation.

This result has applicable outcomes for conservation management on the Hawaiki archipelago. I suggested that weeding effort focus on larger islands and in particular the islands closer to the mainland. Globally, the biogeographical patterns of exotic species are still poorly examined. With insights from this study and other similar research the Theory of Island Biogeography may be an informative approach to dealing with the ominous threat of exotic species. 


\section{Preface and Acknowledgements}

During the last semester of my undergraduate degree I enrolled into Biol222 which sent me on a path to where I am today; about to hand in my MSC thesis. There I met three people without whom my thesis would not be possible

The first and most important person was K.C. Burns who took me in as his postgraduate student many years after. Thank you $K C$ for finding a project that suited me and for motivating me when my focus waned. I wish for you that one of your children become professional footballers or surfers in the future.

The two other people I met on that field trip were Anthony Leung, who helped me immensely with the GIS component of my research and Zak Murray, who guided me during the writing of my thesis. Many thanks for your help and for tolerating me in general.

During my research I relied heavily on the work of my collaborators Peter Bellingham from Landcare Research and Ewen Cameron from the Auckland War Memorial Museum. Thank you both for being great sources of knowledge and support. I wish you best of luck for the continuation of this project afterwards and I hope my contribution will not stop here.

Outside of this project I would like to thank Guillaume Aoustet, Evan Brenton-Rule and Asher Cook who kept me smiling during the difficult stages of my project and Sean Hann my high school teacher who spurned my interest in biology. Finally, to my parents who drove me to continue my education after I was done, thank you for this and so much more. 
Table of Contents

1. Introduction

1.1 General introduction

1.2 Islands are model systems for research

1.3.1 The Theory of Island Biogeography

1.3.2 The two observations of the TIB

1.3.3 Predictions and inferences from the observations

1.3.4 Applications of the TIB

1.3.5 Updating the model

1.4.1 Exotic species

1.4.2 The invasion paradox

1.5 Comparing island biogeography between exotic and native species

1.6 Literature overview

1.7 Study site - The Hawaiki Archipelago

1.8 Thesis Aims

2. Methods

2.1 Spatial maps of the Hawaiki archipelago

2.2.1 Geographical Information Systems (GIS)

2.2.2 Island area measurements

2.2.3 Island isolation measurements

2.3 Flora species lists

2.4.1 General statistical methodology

2.4.2 Statistical methodology for calculating relationships

3. Results

3.1 Species-area relationship

3.2 Species-isolation relationship

3.3 Diversity-invasibility relationship

4. Discussion

4.1 The species-area relationship

4.2. The species-isolation relationship 
4.3 The diversity-invasibility relationship

4.4 General support for the TIB

4.5 Shortcomings

4.6 Further research on the Hawaiki

4.7 Conservation management

4.8 General conclusion

5 References 


\section{Introduction}

\subsection{General introduction}

One of the most striking features of the science of ecology is that species diversity follows geographical patterns. These patterns can be found at all scales of research ranging from small scale experimental (Kennedy et al., 2002; Naeem et al., 2000) to global patterns such as latitudinal gradients (Brown \& Sax, 2004). Biogeography is the branch of ecology dedicated to the study of the geographic distribution of species.

The focus on island systems has been greatly explored in biogeography (Warren et al., 2015) and in particular, gave rise to one of ecology's most celebrated models, the Theory of Island Biogeography (MacArthur \& Wilson, 1963). Over the last 50 years the model has held up to empirical evidence (Losos \& Ricklefs, 2009) and has also been a great success in conservation ecology where it is one of the central concepts (Whittaker \& FernándezPalacios, 2007). However an understudied area of biogeography is the island biogeography of exotics species in their new community (Sax \& Gaines, 2006). The environmental factors that drive native species richness may not have the same influence on exotic species. Understanding the differences between native and exotic richness is imperative for conservation ecology because of the threat of certain exotic species to regional biodiversity (Hulme, 2009; Vitousek, 1977).

\subsection{Islands are model systems for research}

Analyses of insular island systems have played an important role in the development of biogeography and the broader fields of evolutionary and conservation theory. The simplicity of islands allows them to be used as model systems that provide insights into the formation of ecological communities (Warren et al., 2015). The key attributes of islands as model systems in biogeography are 
(1)Islands have clearly defined hard boundaries set by the shoreline. In contrast on continents the range of species is large and it can be difficult to determine clear borders in terms of dispersal and gene flow. These boundaries allow ecologist to infer insular ecological communities.

(2)In general islands are small (compared to continents) and therefore it is feasible to complete comprehensive inventories of species diversity. This is also important because diversity changes with time. On a smaller land area species inventories can be captured in a short space of time.

(3)A common ecological concept is that physical elements of the environment are significant drivers of species diversity. On islands these elements, such as area, elevation, isolation from the source population, geological history, topographic characteristics, soil type and land use are more easily measured.

(4)Across different islands these physical elements naturally vary across a given gradient. Furthermore islands are reoccurring geographical sites across the globe which provides repetitions for research. These characteristics support quantitative study.

It is important to note that these are the important elements of islands for the study of biogeography in particular. This is not intended to be an exhaustive list of all key attributes because there are also major study sites for other fields in ecology. Such a list can be found in Warren et al. (2015).

\subsubsection{The Theory of Island Biogeography}

One of the most important ecological discoveries from the study of islands is undoubtedly MacArthur and Wilson's Theory of Island Biogeography (hereafter TIB) (Wilson \& MacArthur, 1967). Previous studies with success using insular systems encouraged them to conceptualise islands as insular microcosms of communities (Lomolino \& Brown, 2009). Broadly, their theory 
suggests that diversity on islands are dynamic equilibriums balanced by the continuous effects of extinction and immigration (Lomolino, Brown, \& Sax, 2010). Perhaps the authors were not the first to draw the ideas together (Lomolino \& Brown, 2009) however they where they first to conceive and publish a working theory. Over the last 50 years the TIB has become a conceptual foundation in biogeography and ecology as a whole. It has spawned many other ideas such as metapopulation theory (Wiens, 1996) and neutral theory (Hubbell, 2001) as well as applications in conservation ecology (Whittaker \& Fernández-Palacios, 2007).

\subsubsection{The two observations of the TIB}

The TIB was created to account for two widely observed patterns of species richness that had both been described by the 1960s. The patterns that initiated the TIB were:

(1) The species-area relationship; or the positive relationship between species richness and the size of the area of habitat.

(2) The species-isolation relationship; or the negative relationship between species richness and the distance from the source population.

The first observational pattern of the TIB is (1). This is one of the oldest and most persistent patterns in ecology (Darlington, 1957). It describes the positive scaling between the number of species found and the area of sampling. In other words, smaller areas will contain less species than larger areas all other factors being equal. This relationship has been found across different taxa on both mainland and islands (Darlington, 1957; Lomolino, Brown, \& Davis, 1989). Although it is widely regarded as one of ecology's few laws, explanations for the relationship remain varied and are unable to fully explain the diversity of empirical observations. Many explanations seek to explain the pattern and they are well summarised in Blackburn, Delean, Pyšek, and Cassey (2015). 
The second foundation pattern of the TIB is (2). The species-isolation relationship has also been well documented (Lack, 1970; Lomolino et al., 1989). Variation in dispersal ability is commonly suggested as the limiting factor behind this pattern (Long, Trussell, \& Elliman, 2009). Islands that are near the mainland will receive more propagules than distant islands because species differ in the maximum range of dispersal (Rosenzweig, 1995). Moreover they will also receive propagules from a higher number of species. As such near islands have both a higher chance of colonisation from more propagules and a higher pool of potential richness from a higher variation of propagules. However, distance from the mainland may not be the best metric of isolation. In stepping stone theory (Gilpin, 1980) intermediate islands can act as source populations for dispersal outside of the mainland. Also the patterns of oceans and winds, differences in topography with island age and historical land bridges can facilitate or inhibit colonisation (Moody, 2000). 


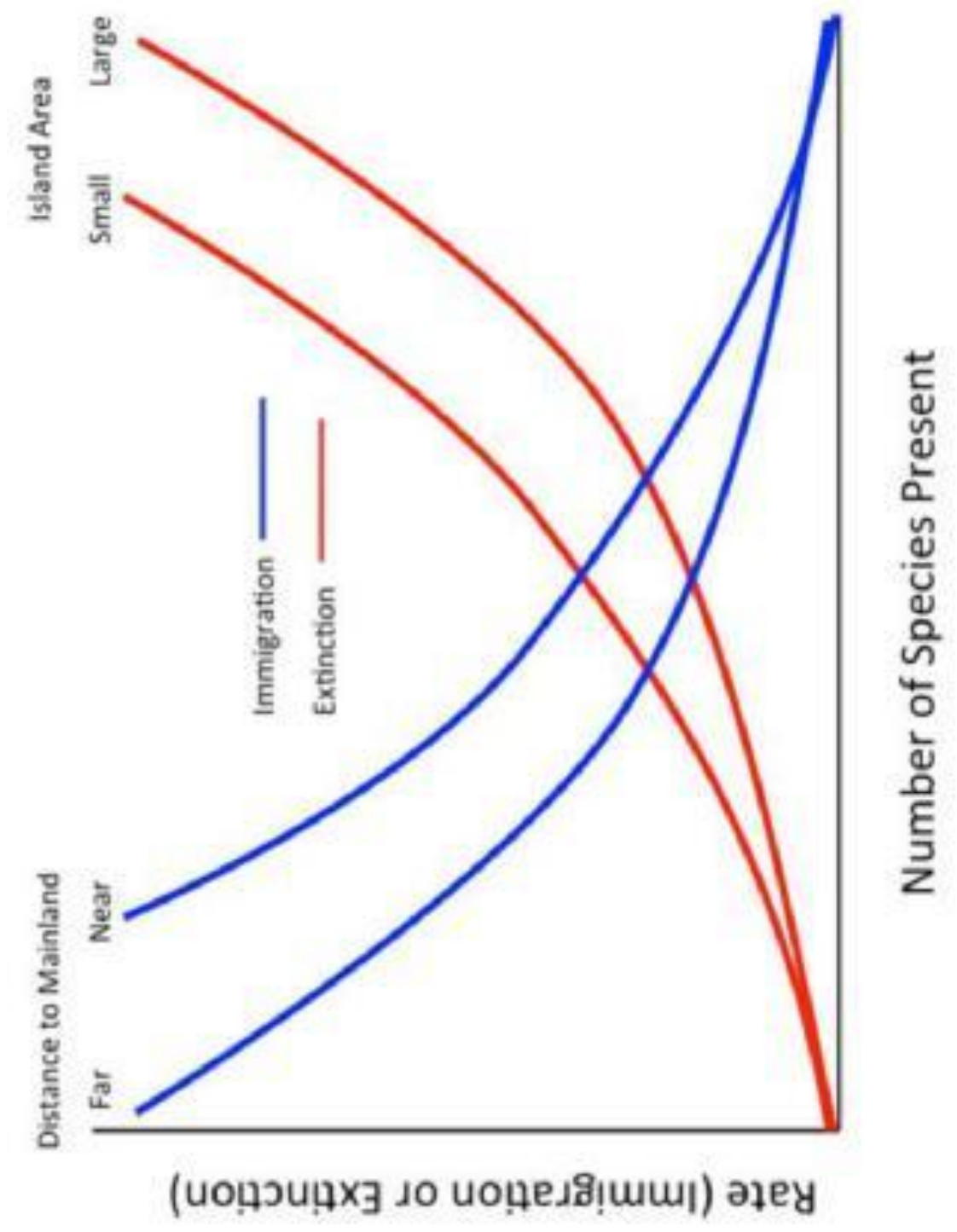

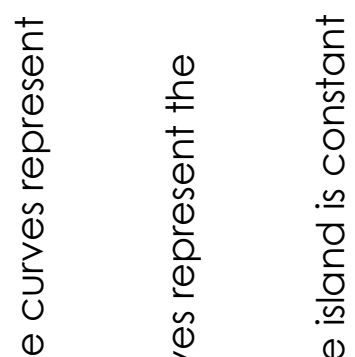

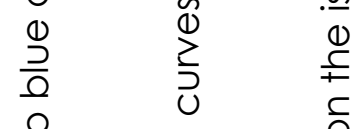

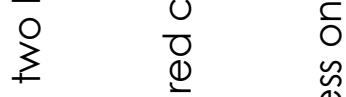

$\stackrel{1}{\models} \quad \stackrel{5}{\frac{0}{c}}$

崩 步

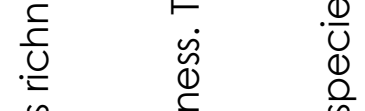

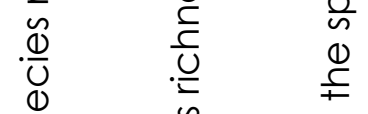

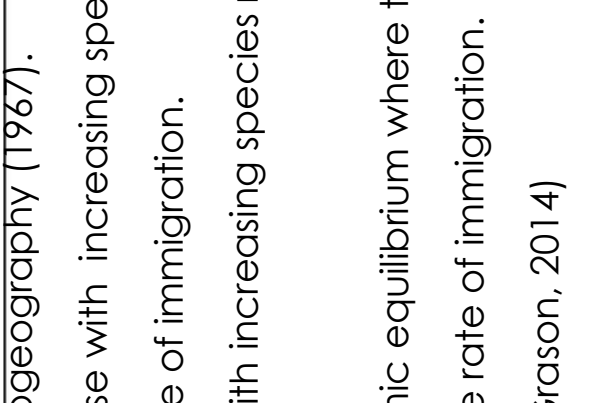

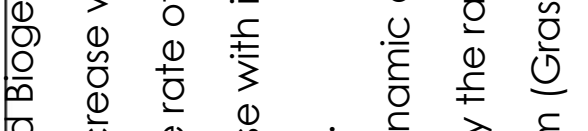

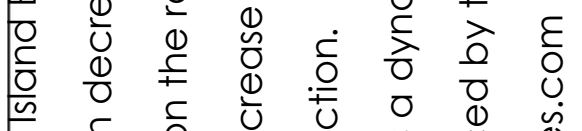

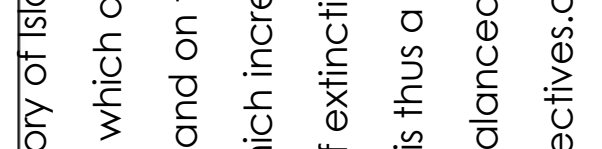

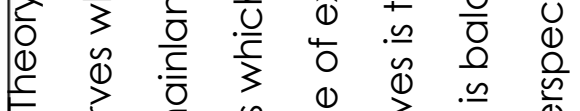

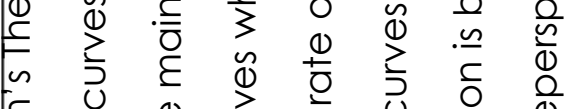

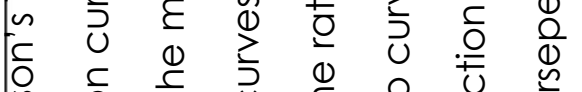

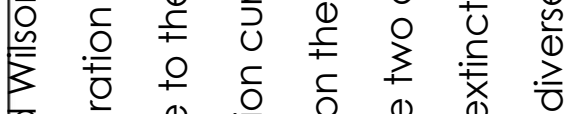

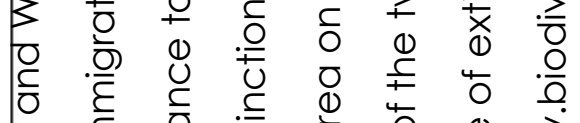

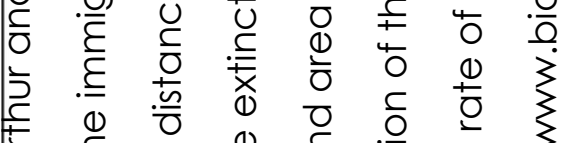

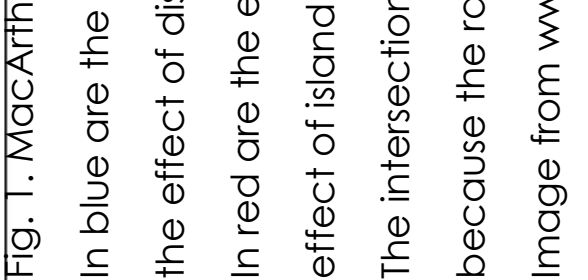




\subsubsection{Predictions and inferences from the observations}

In "An equilibrium theory of insular zoogeography" MacArthur \& Wilson reconciled the species-area relationship and the species-isolation relationship on the study sites of islands. They suggested a working theory where island species diversity should be viewed as a diversity-dependent dynamic balance between immigration and extinction. In order to come to this conclusion they made two key predictions:

(1) The immigration rate for an island decreases as species richness increases; or a negative relationship between immigration rate and richness

(2) The rate of species extinctions increases as species richness increases; or a positive relationship between extinction rate and richness.

These predictions are visualised in Fig. 1. The rate of immigration curve is negative with increasing species richness whilst the rate of extinction curve is positive. The intersection of the two curves is a dynamic equilibrium where the species richness on the island is constant. At the dynamic equilibrium species richness is stabilised because the rate of extinction is balanced by the rate of immigration of new species. The exact species at this point will change continuously, as species turnover occurs, however total species richness remains constant and hence the "dynamic" equilibrium. Since both of the initial predictions, (1) and (2), involve the number of species this equilibrium is diversity dependant.

Based on the dynamic equilibrium the TIB makes two further predictions that incorporate geography into the model:

(3) Islands nearer to the source population will have higher rates of immigration as opposed to islands further away.

(4) Larger islands have lower rates of extinction than smaller islands. 
(3) Leads to the two different curves for immigration pictured in Fig. 1; one for near islands and one for far islands. Similarly, (4) leads to two extinction curves; one for small islands and the other for large islands Fig. 1. These predictions are true provided that the immigration and extinction curves are monotonic and all other factors being equal. From (3) it can then be inferred that nearer islands have more species than more distant islands and from (4) that large islands have more species than small islands. These two conclusions are in fact the two key tenets to the TIB.

\subsubsection{Applications of the TIB}

Perhaps, the greatest success of MacArthur and Wilson's theory is application to conservation. Since islands in the sense of the TIB are "a self-contained region whose species originate entirely by immigration from outside the region" (Rosenzweig, 1995) then under the concept of habitat fragmentation patches of nature reserves in human-altered landscapes can also be considered as islands (Laurance, 2008). By recognising two elements that underlie species diversity the base TIB was thus extrapolated onto a larger scale to indicate mechanisms that drive the global loss of diversity. In terms of the design of nature reserves Diamond (1975) suggested the TIB produced six key principles (Fig. 2). 
Better

A

B

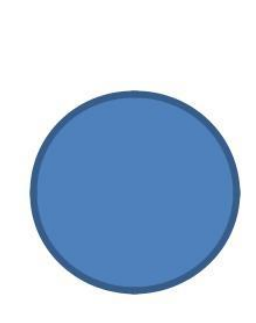

C

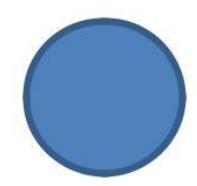

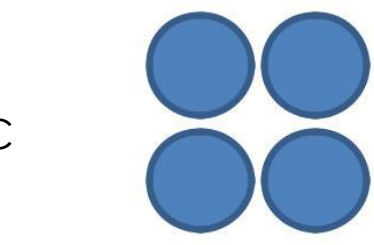

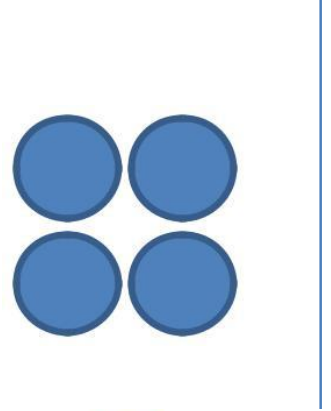

D

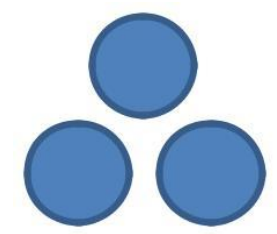

E

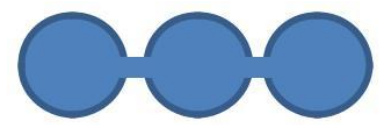

F
Worse
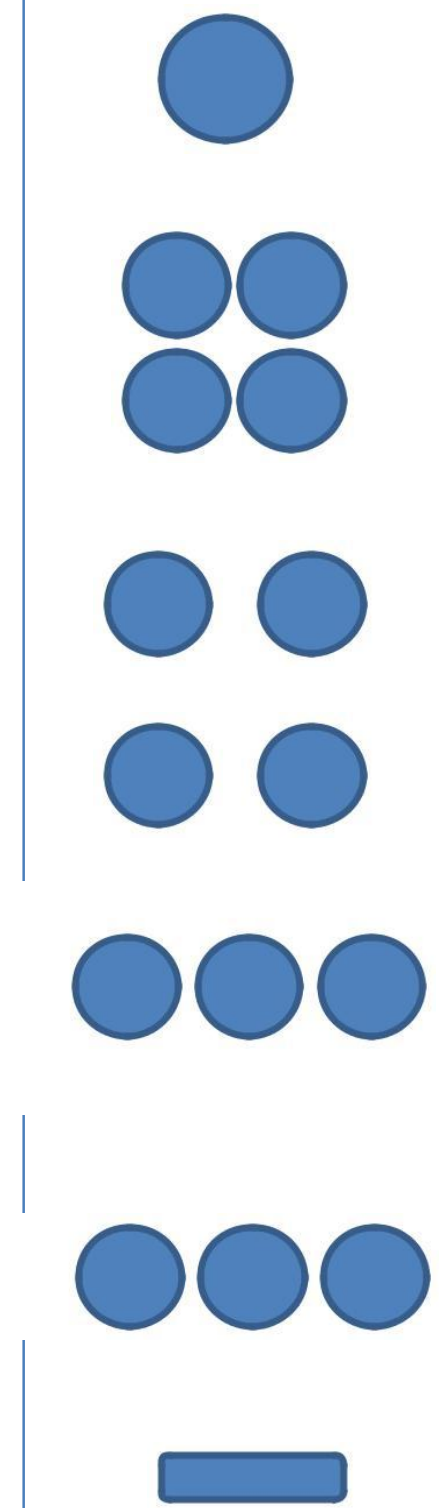

Fig.2. Diamond's six key geometric principles (1975) for the design of nature reserves developed from island biogeography.

A) A large reserve is better than a small reserve

B) A single reserve is superior to several smaller reserves

C) If there are several reserves then they should be as close to each other as possible

D) If there are several reserves then should be spaced equally from another and not spaced in a straight line

E) If reserves are linear then they should be connected by nature corridors

F) Circular reserves are better than linear reserves 
His paper was widely discussed in ecology and provoked what is termed the single large or several small (SLOSS) debate. Critics to Diamond's line of thought argued that reserves should in fact be multiple smaller reserves comprising the total area of the larger reserve (Simberloff \& Abele, 1976) because the species on smaller metaphorical islands are not necessarily subsets of the large island. The critics, led by Dan Simberloff, considered Diamonds paper to be a dangerous over-simplified model for conservation. Broadly, Simberloff suggests that habitat diversity is either as or more important than reserve size in shaping the number of species protected (Simberloff \& Abele, 1976). The SLOSS debate is still ongoing (Mackey et al., 2015) and has been described as "ecology's own gentle version of trench warfare" (Quammen, 2012). That said, regardless of the outcome of the SLOSS debate the TIB has already proved to be a central theory in applied conservation.

\subsubsection{Updating the model}

In the last 50 years MacArthur and Wilson's model has been a fundamental paradigm in ecology. Paradigms however are made to be reconsidered, broken and ultimately upgraded. Over the lifetime of the TIB empirical research has unearthed its strengths but also its shortcomings. In general, the strongest criticism of the model is the under-representation of evolutionary processes and the 'general dynamic theory' by Whittaker, Triantis, and Ladle (2008) is the leading work addressing this perceived flaw.

However a different weakness of the TIB and one that is much less investigated in the literature, is the lack of distinction between native and exotics species. The dichotomy between native and exotics species presents natural gradients in species richness that lend towards studies of TIB. Although a positive element of the TIB is its simplicity modifying the theory to account for the differences between native and exotic species could foster tremendous applications in conservation (Burns, 2015). 


\subsubsection{Exotic species}

Exotic species can be defined as species whose presence in a region is attributable to human actions, which have enabled them to overcome fundamental biogeographical boundaries (Blackburn et al., 2011). The seminal work in the discipline of invasion biology was "The Ecology of Invasions by Animals and Plants" by Elton (1958) but the field only began to take shape in the early 1980s (Davis, 2009). Publications on invasion biology have become popular as the importance of conservation and species diversity has come to the forefront of ecological literature.

Currently, biotic invasions are widely considered to be a major threat to global biodiversity (Pimentel, Morrison, \& Zuniga, 2005; Vitousek, 1977) Different explanations for the success of certain exotic species in new geographical areas have been postulated. In general these are (1) competitive advantages over natives (Daehler, 2003), (2) the release from natural predators (DeWalt, Denslow, \& Ickes, 2004) and (3) novel traits in new communities or environmental conditions (Vitousek, 1990). Predicting the outcome of invasions has been challenging and thus biotic invasions are a key concern for conservation (Sax, Gaines, \& Brown, 2002; Strayer, Eviner, Jeschke, \& Pace, 2006).

Elton theorised that communities rich in native species restrict the colonisation of exotic species better than species-poor communities. This is known as "the biotic resistance hypothesis" (Elton, 1958). The rationale behind his hypothesis is the concept that communities rich in native species fill the niches better and thus the competition for resources is stronger within the community. As such communities rich in native species are better able to resist the establishment of exotic species through a variety of biotic factors. This thought therefore infers that exotic and native richness should be negatively correlated. For conservational practices the "biotic resistance 
hypothesis" would therefore suggest that maintaining native species diversity is important in resisting the threat of exotics species. Species diversity is meant in the sense of both species richness and species evenness, or the number of individuals of each species. The relationship between exotic and native species richness is termed the diversity-invasibility relationship (Levine \& D'Antonio, 1999).

\subsubsection{The invasion paradox}

A hypothesised negative diversity-invasibility relationship has been observed in both empirical and experimental studies at small scales, often at $10 \mathrm{~m}_{2}$ or less (Kennedy et al., 2002; Shea \& Chesson, 2002). There has also been confirmation that the observed pattern is driven by the biotic resistance of species-rich communities as predicted by Elton (Naeem et al., 2000; Stachowicz, Whitlatch, \& Osman, 1999). However when the diversityinvasibility relationship is examined at board spatial scales the result is inversed. There is no negative correlation and in fact it is often found to be positive (Brooks, Lockwood, \& Jordan, 2013). To explain this pattern at larger scales Stohlgren, Barnett, and Kartesz (2003) suggested that larger areas that can support many native species can also support many exotic species and thus "the rich get richer". This is termed the biotic acceptance hypothesis (Stohlgren et al., 2006). The two conflicting results of the diversity-invasibility relationship come from independent lines of research and constitute what is now known as the "invasion paradox" (Fridley et al., 2007).

It has been suggested that the invasion paradox may simply be the result of spatial scale (Fridley et al., 2007). As the size of the surveyed area increases so does the importance of environmental factors. The relative effect of biotic interactions therefore decreases (Knight \& Reich, 2005; Shea \& Chesson, 2002) However some publications have also reported the lack of a negative relationship even at small scales (Guo, 2015). An alternative hypothesis to the paradox is that the diversity-invasibility relationship is time- 
dependant. The correlation has been observed to change from negative to positive with (Clark \& Johnston, 2011). This suggests that with time exotics are subject to the same processes that shape native richness such as dispersal, disturbance and recolonisation) so the relationship becomes positive (Clark, Johnston, \& Leung, 2013).

Research into the invasion paradox has suggested that natural processes drive native and exotic species richness independently. Then, the question that arises is do natives and exotics respond differently and furthermore are the differences in their patterns of richness, if any, still predictable by the TIB?

\subsection{Comparing island biogeography between exotic and native species}

The literature comparing species-area and species-isolation relationships between exotic and native species is relatively poor given the number of publications addressing those relationships in general (Sax \& Gaines, 2006). The first study to explicitly consider the species-area relationship between native and exotics was (Crawley, 1987). He found that although both species-area relationships were significant and positive the slope was steeper for natives. In other words natives and exotics responded differently to area and native richness was more heavily influenced. Other empirical studies have also shown the opposite scenario where the slope is steeper for exotics (Pyšek, 1998) as well as cases with no significant difference in slope (Blackburn et al., 2015).

In terms of the species-isolation relationship exotic and native species in the same community have also shown contrasting responses. There is not always a significant richness-isolation regression in exotic species (Kueffer et al., 2010; Moody, 2000) but when there is the slope is different to that of natives (Long et al., 2009). 
To summarise, the current literature suggests that although the underlying processes remain unclear (1) island area acts positively on both native and exotic species richness (2) isolation can act in both positive and negative ways on both sets of species. The magnitude of response also varies between native and exotics which is intuitive because natural processes are unlikely to influence both native and exotics exactly the same way.

\subsection{Literature overview}

In summary, there has been a lack of consistent outcomes in the literature on the diversity-invasibility relationship as well as the influence of geological factors compared between native and exotics species richness. MacArthur and Wilson's model has played a pioneering role in conservation since its conception but it fails to distinguish between native and exotic species. This distinction is critical because the threat of biotic invasions is a central problem in global conservation (Vitousek, 1977). Although some argue that exotic species are not dangerous to global diversity (Davis et al., 2011) understanding how exotic and native species respond differently to physical gradients can nonetheless inform ecologists about how biotic factors influence community composition.

\subsection{Study site - The Hawaiki Archipelago}

The choice of islands as study sites has been widely successful in biogeography (Warren et al., 2015) and thus for my research a set of New Zealand islands was used. The study site starts at the nearshore islands in the the Bay of Plenty on the east coast of the North Island and heads north all the way to the top of the Coromandel peninsula including a few from the top of the west coast (Fig. 3). These include groups such the Cavalli Islands, the Poor Knights Islands and the Hen and Chicken Islands. These islands offer wide gradients in physical geography, in particular those relevant to the TIB, as well as considerable variability in exotic and native species richness. For the purposes of this study this set of islands will be called the Hawaiki archipelago. 
In short, my research is an assessment of the species-area and speciesisolation relationships found on the Hawaiki archipelago for native and exotic plant species. The use of flora to understand macroecological patterns has been tremendously valuable (Kreft, Jetz, Mutke, Kier, \& Barthlott, 2008; Sax et al., 2002). For this study flora species lists were collected from a wide range of both published and unpublished literature. This was done in collaboration with Peter Bellingham from Landcare Research and Ewen Cameron from the Auckland Museum. The physical geography of islands where determined using techniques in ArcGis 10.2 from the Topo50 map dataset retrieved from www.linz.govt.nz. 


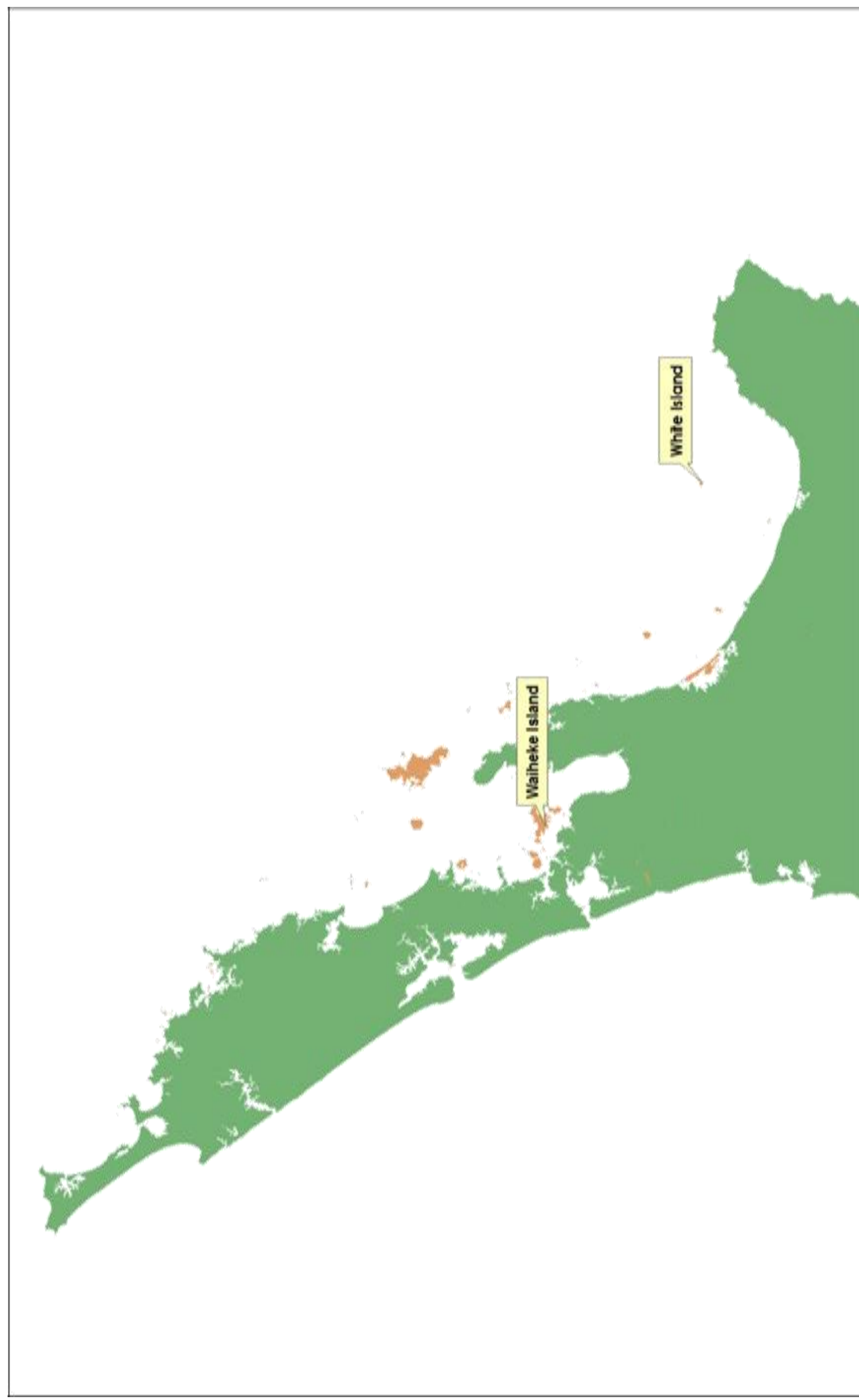

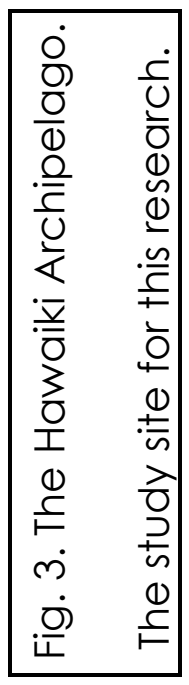

20 


\subsection{Thesis Aims}

The overall goal of this research is to discover any variation in the influence of physical geography between native and exotic species. The specific aims of the research are to understand:

(1) How exotic species richness correlates to natives

- Hypothesis - a positive scale in line with the invasion paradox

(2)If the TIB can also be used to explain patterns of exotic richness

- Hypothesis - area and isolation will also explain exotic richness

(3)And if so what are the differences between the patterns of exotic and native richness.

- Hypothesis - no difference in the patterns between exotic and native richness.

\section{Methods}

\subsection{Spatial maps of the Hawaiki archipelago}

I collected high resolution maps of the Hawaiki archipelago from Land Information New Zealand's website http://www.linz.govt.nz/. The two important data layers for the study were:

(1) NZ Island Polygons (Topo, 1:50k) (LINZ)

- which contains spatial data on all of NZ's nearshore islands

(2) NZ Coastlines (Topo, 1:50k) (LINZ)

- which shows the geographic limits of New Zealand's mainland

\subsubsection{Geographical Information Systems (GIS)}

These data layers where combined into one data frame on ArcGIS10.2 under the commonly used NZGD 2000 New Zealand Transverse Mercator coordinate system and the Transverse Mercator projection system. I then resized the data frame to only encompass the north island in order to accelerate future calculations. 


\subsubsection{Island area measurements}

To obtain island area the coordinates of the islands were found from searches on http://www.topomap.co.nz/. Failing that island size was found from the publication containing the flora species list. These coordinates were then used in the 'Go To XY' function to identify the polygon in the data frame corresponding to the islands. This was confirmed by crosschecking the name of the target island with the name in the attribute table of the polygon.

Finally, the 'Calculate Geometry' tool supplied the size of the target island.

\subsubsection{Island isolation measurements}

Distance to the mainland is the traditional measurement for isolation in the study of island biogeography. To obtain the distance to mainland of each island the 'Polygon To Line' tool was used to turn the NZ coastlines shapefile into a line shapefile. Next the 'Generate Near Table' tool calculated the closest distance between the target island and the NZ coastline (Settings - in: target island polygon, near: coastline polyline).

Similarly to Diver (2008), the area of land in a given circumference around each island was also calculated. This was done at distances of $250 \mathrm{~m}$, $500 \mathrm{~m}$ and $1 \mathrm{~km}$ around each island forming three separate concentric circles. The percentage of land in each concentric circle was averaged over the three distances to give an alternative measure of isolation. In this metric islands with a low percentage of land were deemed more isolated than those with a high percentage. A model was created to calculate these concentric circles (Fig. 4). Additionally, I merged all the polygons on the island polygons dataset with the coastlines shapefile to create a shapefile which contained all the land in the study site. The model first used the 'Buffer' tool to draw the concentric circle around the selected island at the designated distance. The model then used the 'Intersect' tool to determine the overlapping area between the concentric circle and a shapefile 
containing all land in the study site (Fig. 5). 'Outside Only' was selected as the 'Side Type' in the 'Buffer' tool to exclude the area of the target island itself.

\subsection{Flora species lists}

The species lists of the archipelago were collected from a variety of both published and unpublished work and amalgamated into a single dataset. The relevant literature used to represent each island was suggested by my collaborators and in particular, Peter Bellingham. Journals such as Tane the journal of the Auckland University Field Club and the New Zealand Journal of Botany were used. Ewen Cameron also solved all issues on species names synonyms, determining exotic species and general nomenclature. These species lists were completed for over 200 islands, however a few were too small to appear on the spatial maps so the final study site encompassed 186 islands. 


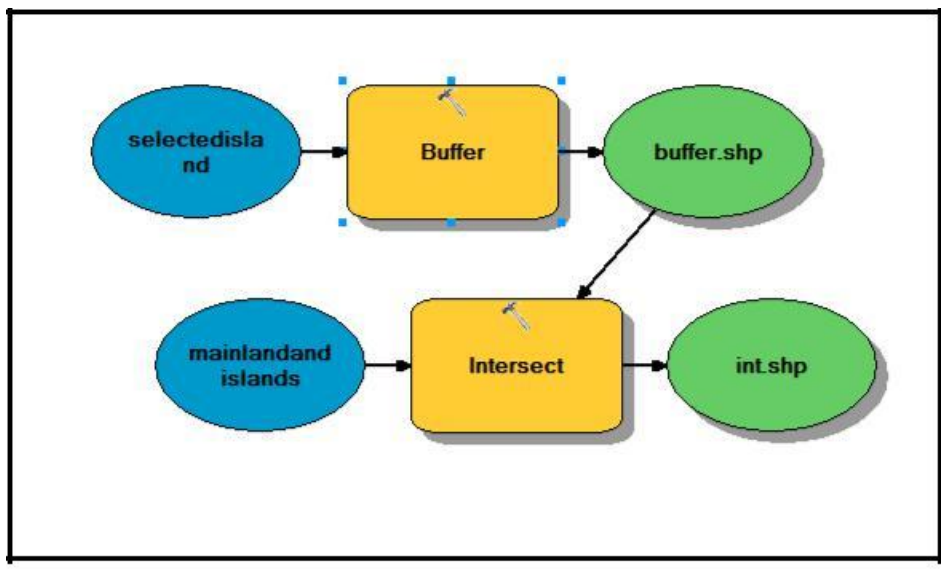

Fig. 4. The ArcGis Model used to construct the concentric circles metric of isolation in ArcGIS 10.2.

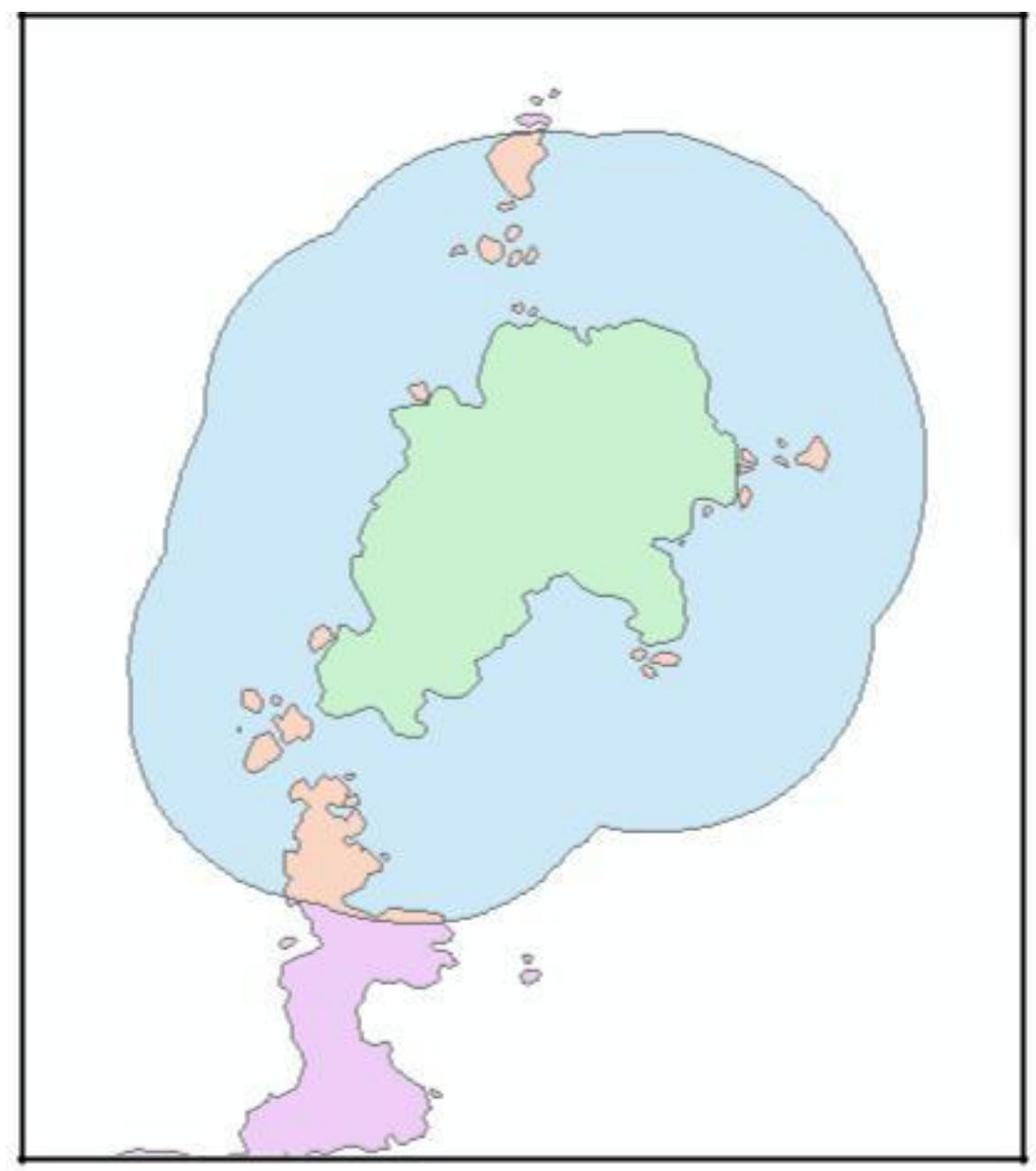

Fig. 5. A visualisation of how the concentric circle metric was calculated in ArcGIS 10.2. Key: Green- Target Island. Purple - Other land. Blue - The Buffer area at the determined distance around the island. Beige - The land inside the buffer area calculated by Intersect tool.

Islands with more beige areas are said to be less isolated (from other land). 


\subsubsection{General statistical methodology}

For all data analyses I used the SPSS version 22 statistical package. The statistical tools I employed were:

(1) Simple Linear Regressions were used to assess the relationships between native species, exotics species, island area and island isolation.

(2) To ensure that the data conform to normality, the In function was used on variables where necessarily due to positive skewing.

(3) Furthermore, In (species richness +1 ) was used because in some cases islands had no native, no exotic or no species in general.

\subsubsection{Statistical methodology for calculating relationships}

(1) Species Area Relationships

I regressed In (species richness +1 ) as a function of In (area) in both natives and exotics.

(2) Species Isolation Relationships

To account for the dominating effect of area on richness species isolation relationships were analysed independently of the effect of area. In order to achieve this the residuals from the species area regressions were then regressed themselves as a function of isolation for exotics and natives independently. This statistical analysis was completed for both metrics of isolation, distance to mainland (hereafter distance) and concentric circles.

(3) Diversity-Invasibility relationship To evaluate the relationship between exotic and native richness a Pearson product-moment correlation coefficient was calculated. 


\section{Results}

\subsection{Species-area relationship}

Area was a significantly positive predictor of exotic richness (Fig. 6a); (In (exotic richness) $=0.29 \times \ln$ (island area) $-0.06, R_{2}=0.31, P<0.01$ ) as well as native richness (Fig. 6b); (In (native richness) $=0.27 \times \ln$ (island area) $+0.75, R_{2}$ $=0.35, P<0.011$.

\subsection{Species-isolation relationship}

Both exotic and native plant richness significantly decreased with distance from the mainland when analysed independently of area (Fig. 7) (exotics, P < 0.01 ; natives, $\mathrm{P}<0.01$ ). However, the strength of the effect of distance to mainland varied between exotics and natives. Distance explained more of the variation in exotic richness than native (exotics, $R_{2}=0.11, P<0.01$; natives, $\left.R_{2}=0.04, P<0.01\right)$. The negative slope was also stronger for exotic species than for natives (Fig. 7) (exotics: $y=-0.19 x$; natives: $y=-0.11 x$ ).

To further understand the differential effect of distance to mainland between natives and exotics, the percentage of species that are exotic was regressed against In (distance). There was a significant decrease in the percentage of exotics species with distance. (Fig. 8) (proportion of exotic species $=-0.04 \ln$ (distance $\left.)+0.53, R_{2}=0.12, P<0.01\right)$. The alternative metric for isolation of concentric circles similarly showed that exotic richness decreased in more isolated islands $(P=0.02)$ but was not significant for native richness.

\subsection{Diversity-invasibility relationship}

Native and exotic richness were strongly and positively correlated on islands in the archipelago. A Pearson product-moment correlation coefficient showed a significant, strong and positive correlation between exotic and native plant richness. (Fig. 9) $\left(\mathrm{R}_{2}=0.85, \mathrm{P}<0.01\right)$. 

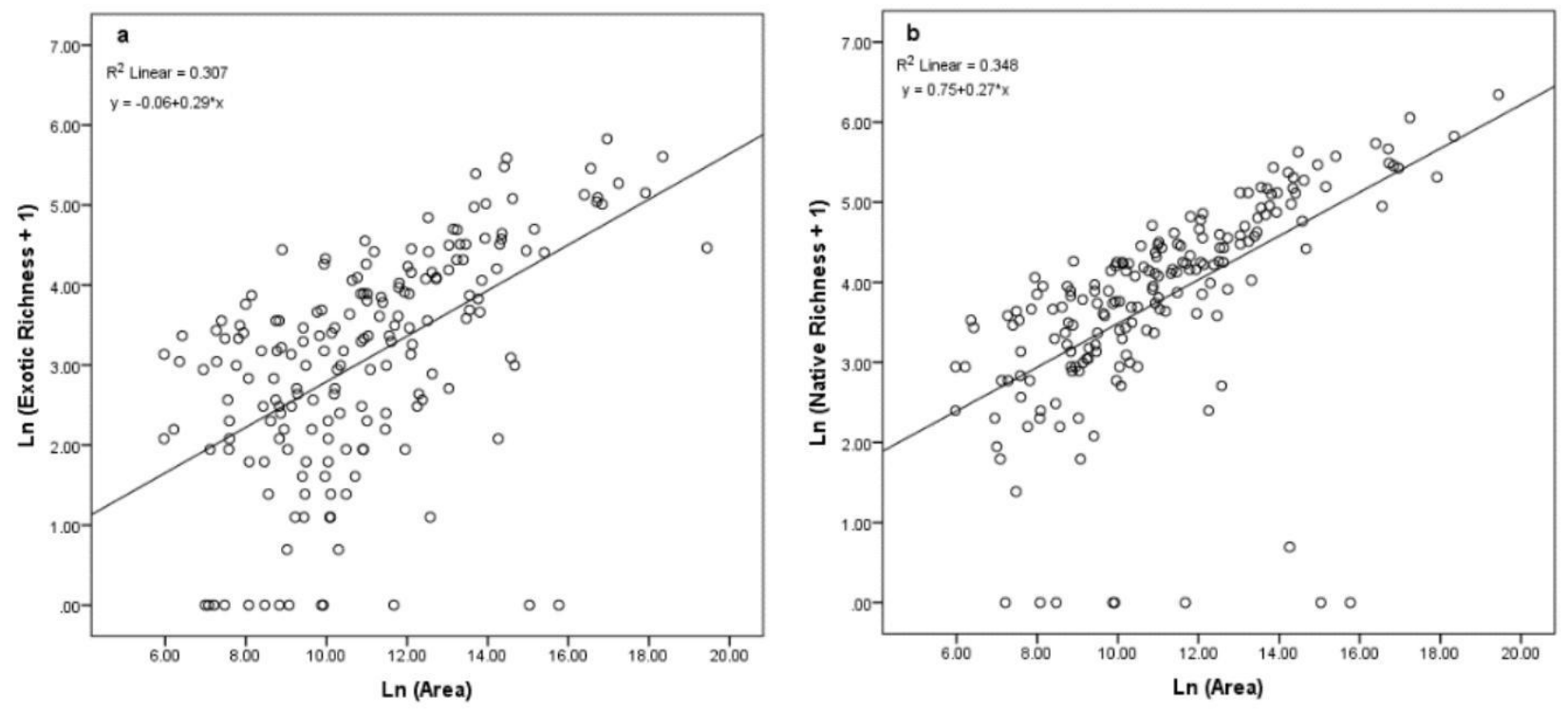

Fig. 6. The relationship between richness and area (originally measured in $\mathrm{m}_{2}$ ) for (a) exotic species and (b) native species of plants in the Hawaiki archipelago $(N=186)$. Fitted regression lines are shown along with their equation and the $R_{2}$ values.
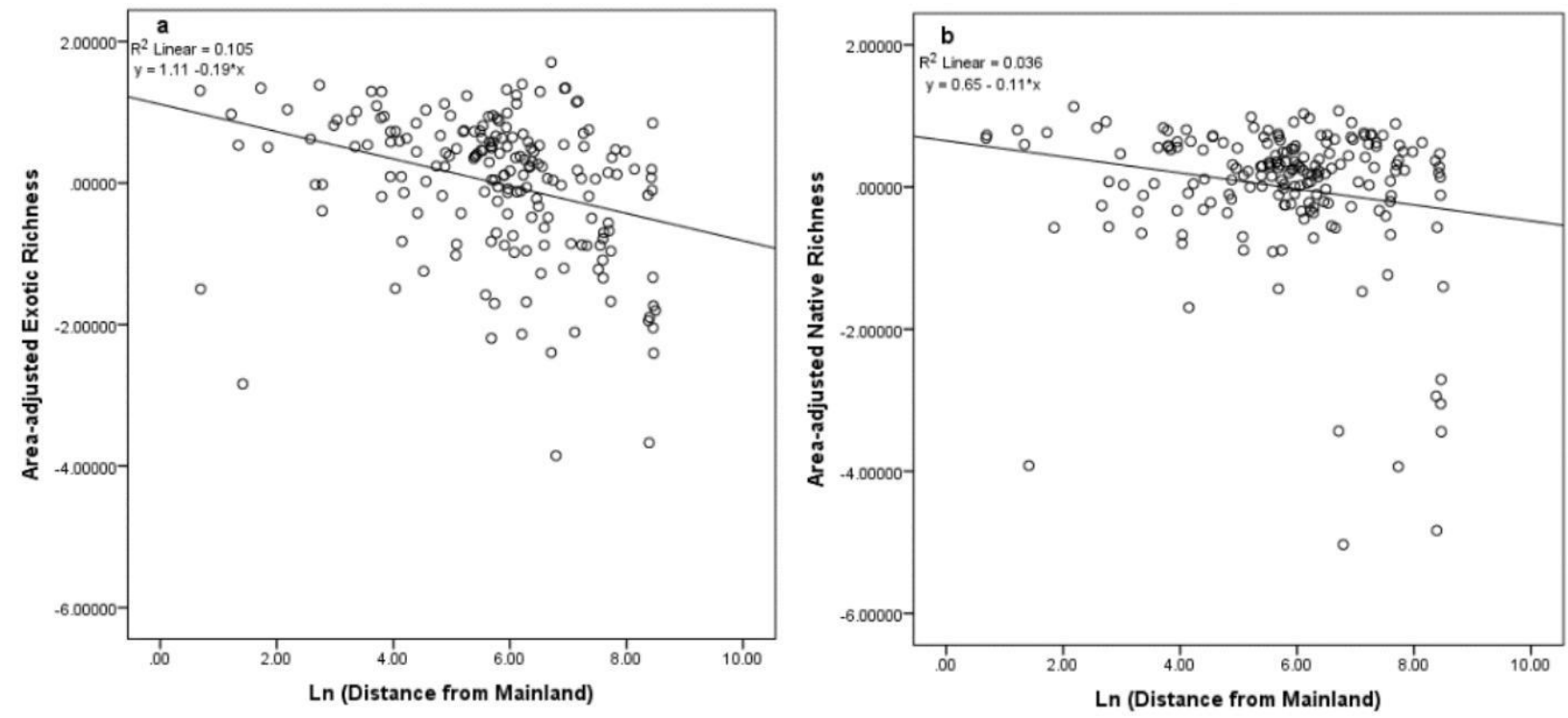

Fig. 7. The relationship between species richness after removing the effects of area (the residuals from the species-area regressions) and distance from mainland (originally measured in $\mathrm{m}$ ) for (a) exotic species and (b) native species of plants in the Hawaiki archipelago $(N=186)$. Fitted regression lines are shown along with their equation and the $R_{2}$ values. 


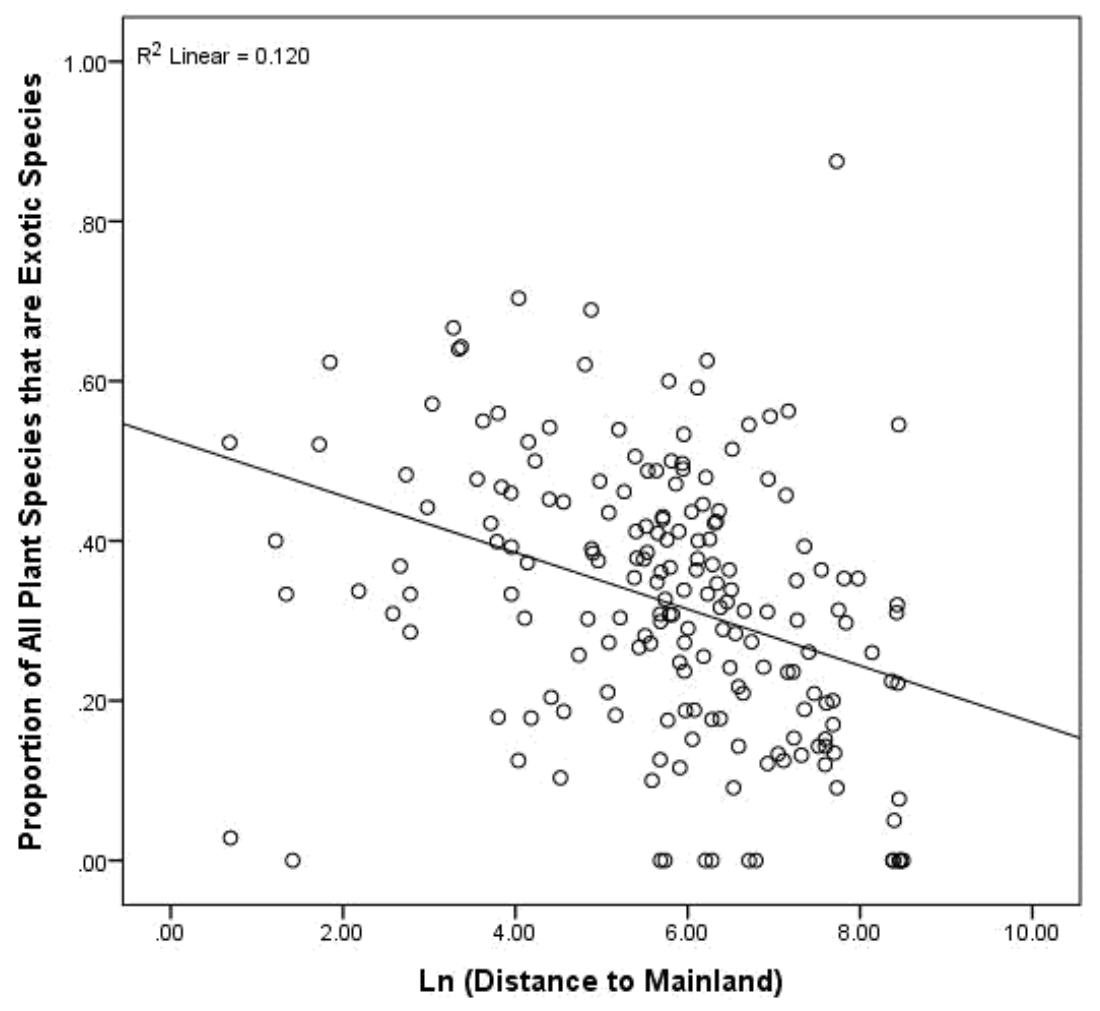

Fig. 8. The proportion of all plant species that are exotic species as a function of distance from mainland (originally measured in $\mathrm{m}$ ) on the Hawaiki archipelago $(N=186)$. Fitted regression line is shown along with the $R_{2}$ value.

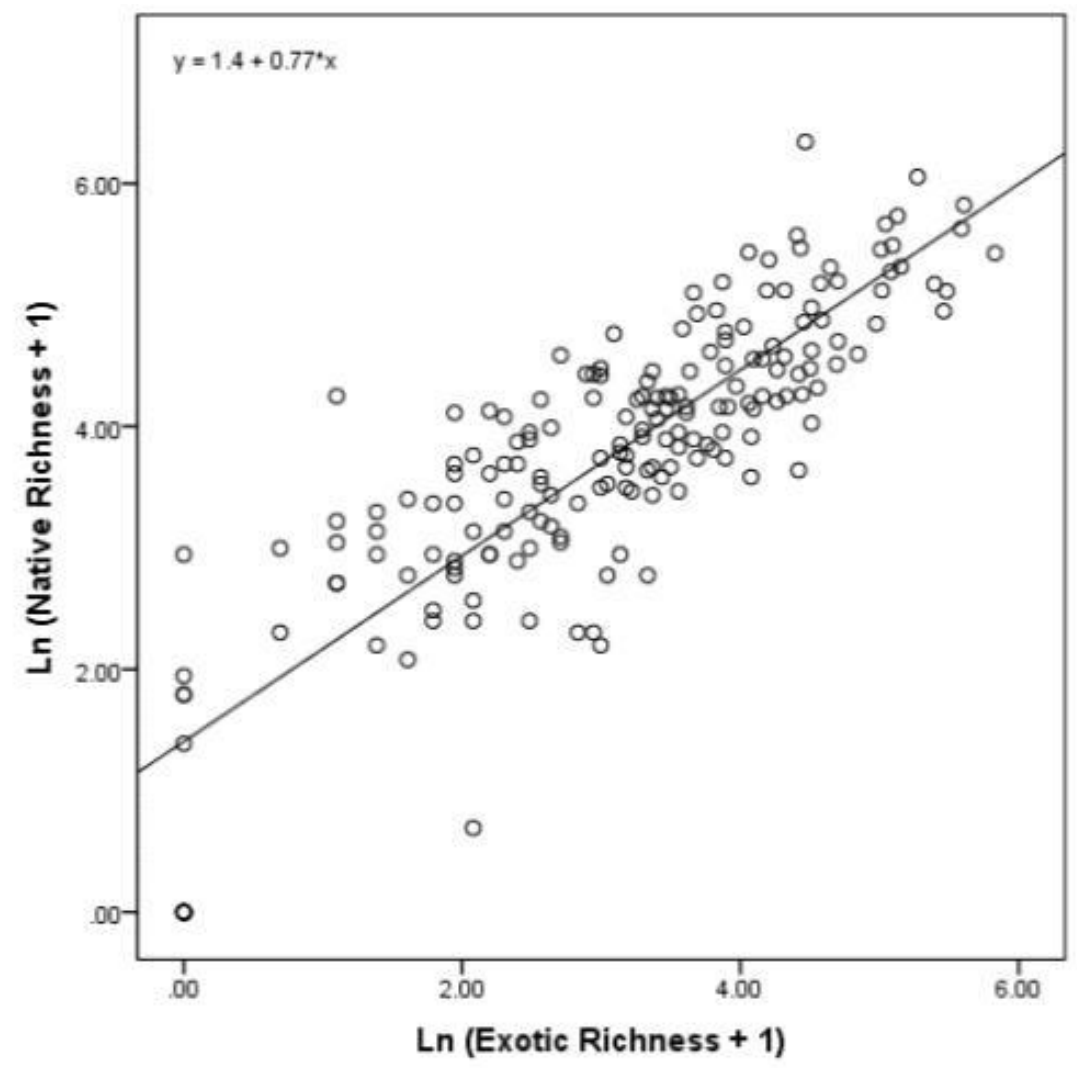

Fig. 9. The correlation between native and exotic richness of plant species on the Hawaiki archipelago $(N=186)$. Each data point represents the number of native and exotic species on an island. The fitted regression line and its equation is shown. 


\section{Discussion}

\subsection{The species-area relationship}

Given its widely observed influence on the patterns of species richness globally, a comparison of the species-area relationship between exotic and native richness is a logical starting point. I hypothesised that the same arearichness pattern predicted by island biogeography in natives would also be quantitatively similar to that of exotic species. An almost identical positive scaling in richness with island area was observed (Fig. 6). With respect to the TIB this suggests that common processes underlie the slope of this relationship in both sets of species. For example the rate of extinction is hypothesised to be lower on larger islands and this result implies that this occurs equally in natives and exotics.

These results are congruent with the biotic acceptance hypothesis (Stohlgren et al., 2006). The hypothesis holds that habitats are either good or bad for species in general. Thus habitats that were originally good for natives were also good for newly-arrived exotics and thus the "rich get richer" (Stohlgren et al., 2003). Larger islands should, in general, hold higher habitat heterogeneity. It follows that there is increased niche availability which supports higher species richness. Therefore larger islands are "good" habitats for native species and, as the hypothesis predicts, they seem to be similarly "good" for exotics. However larger islands do not necessarily have greater habitat heterogeneity than smaller islands because of differences in island topography. Thus to find comprehensive support for the biotic acceptance hypothesis, higher native richness should match higher exotic richness outside of the parameters of island biogeography. A strong positive diversity-invasibility relationship, similar to what was observed, is consistent with this prediction.

Sax and Gaines (2006) described similar results to this study. Their research on plant species in the California Channel Islands and on Oceanic 
Islands showed an increase in richness for both exotic and native species. For the Channel Islands they found the proportion of natives to be higher, similarly to our study, however the slopes of the regressions differed between the two sets of species. This inconsistency was explained by variation in the effect of isolation from the mainland between the two sets. On the other hand their research on the oceanic islands showed almost identical arearichness slopes as well as a tight diversity-invasibility relationship which were comparable to my results. In a recent study Blackburn et al. (2015) also found comparable results in terms of both similar regression slopes and a strong diversity-invasibility relationship in plants. It was suggested that the positive exotic species-area relationship occurs because the size of the island influences native richness and the degree of human impact. Whilst Sax and Gaines do not explicitly offer explanations to the pattern Blackburn's suggestion is not contradicted by my research and could serve to be a working hypothesis in the future.

To summarise, the positive correlation between the area of sampling and the number of native species is one of the canonical relationships in ecology (Rosenzweig, 1995). As observed in this study and the majority of similar studies, this relationship is not just limited to native species; exotic species richness also increases with area. The underlying factors in this pattern are unclear which make it an important topic for both the fields of biogeography and invasion ecology.

\subsection{The species-isolation relationship}

In comparison the pattern of species isolation relationships for exotic species are unclear. I hypothesised, in accordance with the TIB, that both exotic and native richness would decrease with distance from the mainland and this was the pattern that was observed (Fig. 7). Interestingly, the effect of distance was more influential on exotic species and this resulted in a significantly decreasing proportion of exotics with increasing mainland isolation (Fig. 8.). 
This quantitatively different relationship between the assemblages of both sets of species is indicative of varied biotic responses to isolation.

It has been suggested that more isolated islands are less resistant to establishing exotics because either the endemic plants on such islands are weak competitors (J. S. Denslow, 2003) or because species diversity is relatively low (Kueffer et al., 2010). These ideas suggest that the proportion of exotic species should increase with distance from the mainland or, in other words, the opposite pattern to what was observed. One idea that can explain the deviation in this study from the expected relationship is that exotics species are more dispersal limited than natives. Although more isolated islands are weaker at defending against exotic species those species do not disperse far enough to reach those islands. In any case this result, that distance to mainland influences exotic species differently, demonstrates that biotic traits and not just environmental factors are important in structuring communities.

The results for the species-isolation relationship differ from other studies which have also analysed the same relationship after removing the effect of area. Moody (2000) found that isolation only had a significant relationship on native species and not exotics although the slope was negative. However this study site only contained 8 islands which, when compared to my study site of almost 200, explains the stark difference. A more nuanced approach was taken in a paper published by Long et al. (2009) in Ecology. Research on the plant richness from 25 islands in the Boston harbour exhibited consistent results with the TIB in both exotic and native species as well as a strong diversityinvasibility relationship. These results are strongly consistent with the Hawaiki dataset and similarly Long (2009) also reported variation in the influence of isolation from the mainland on exotics compared to natives. Their key result however was that the isolation effect was significantly stronger in native species which resulted in a higher proportion of exotics with increasing 
isolation; the opposite pattern to what was observed in my study. These contrasting patterns are compounded by the fact that both studies were observed in studies on similar geographic and time scales.

Such contradiction only serves to highlight the need to improve our understanding of island biogeography on exotic species. In particular, the species-isolation relationship for exotics is still poorly understood (Long et al., 2009). There is however promise that the pattern of this relationship may be influenced by biotic factors and thus important in predicting the outcome of future immigration of exotics.

\subsection{The diversity-invasibility relationship}

With the threat of exotic species in ecological communities around the world the diversity-invasibility relationship is a pattern which is increasingly examined. Richness of native plant species was correlated to exotic plant richness as hypothesised (Fig. 9). This was not surprising as all medium and large scale studies reviewed have reported similar patterns. There are two hypotheses explaining the observed positive diversity-invasibility relationship.

The first suggests that the relationship is scale-dependant because at larger scales the relative influence of biotic factors is reduced in comparison to environmental factors (Fridley et al., 2007; Knight \& Reich, 2005). With respects to my research the study sites were naturally occurring islands with the smallest being Calf Island at $391 \mathrm{~m}$. Small scale studies exhibiting a negative diversity-invasibility relationship have generally been experimental studies at 10m2 or less (Guo, 2015). As such my observed result of a positive diversity-invasibility relationship from a large scale study is consistent with that of the scale-dependent hypothesis.

The second hypothesis is that the relationship is time-dependant; with time the same environmental factors that shape native richness also shape 
exotic richness (Clark \& Johnston, 2011). The islands from my research have been above sea level for around 100 years at a minimum and most for far longer (McSaveney, 2013). In the time-dependant hypothesis it is suggested that the shift to a positive correlation from an initially negative relationship is dependent on the fecundity of exotics. The earlier exotic species become established in a community the earlier they become subject to the same post-introduction processes as native species (Clark et al., 2013). Over a minimum of 100 years it can be assumed that such effects have taken place and thus the time-dependant hypothesis is consistent with my results.

In summary, the positive diversity-invasibility relationship I observed is in accordance with the literature. Both scale and time dependant hypotheses have been suggested to explain this pattern of diversity and my results are consistent with both.

\subsection{General support for the TIB}

The species richness on almost 200 islands in the Hawaiki archipelago closely followed the patterns predicted by MacArthur and Wilson's TIB. In the isolation-richness regressions there were species richness values that deviated slightly from the expected patterns for exotic species. It is with such occurrences however that ecologists can make predictions about the roles of other non-island biogeography factors. By themselves such little deviations from the general pattern do not change the overwhelming support for the TIB. Aside from global meta-analyses of the TIB (Blackburn et al., 2015; Sax et al., 2002) this study has one of the highest numbers of replicates in related literature. This study thus shows strong empirical evidence for the TIB which is particularly relevant given the recent literature implying the need for an updated model (Whittaker et al., 2008). 


\subsection{Shortcomings}

Distance to mainland may not be the best predictor of isolation because plants can use intermediate islands as stepping stones to disperse to more isolated islands (Gilpin, 1980). To take advantage of techniques made possible by GIS I used a technique similar to that used by Diver (2008) which calculated concentric circles in order to create an alternative metric for isolation. Similarly to Diver I found the expected negative relationship between isolation and richness after accounting for the effect of island area. Although it was significant the slope of the relationship was weak and it explained less of the variation than the standard distance to mainland metric. Ideally, I would have calculated step isolation as the metric for island isolation. In order to calculate step isolation the island nearest to the target island is firstly identified. If this new island is closer to the mainland than the original island then the measurement for the distance to mainland from the new islands is also applied to the original target island. To account for multiple stepping stones this method is repeated for the new target island and so on and so forth. Such a calculation was too demanding for me to complete on almost 200 islands and so the method with concentric circles was applied instead. Although it was left unused in the statistical analysis this technique did show promise given the significant result and consistency with the expected pattern. In particular it could be useful in large studies such as this one where it is not feasible to calculate multiple step isolation.

Although it was done to the best of my ability the collection of data was not perfect. The surveys forming the plant species lists were conducted at different times and by different people which creates error. There could also have been human error when combining these lists into the single database from each survey. Finally, the set of islands used in the study was not exhaustive of the entire archipelago. 


\subsection{Further research on the Hawaiki}

The database I assembled represents a wealth of information for further studies on the TIB and with particular respect to the patterns of exotic richness. One element of the physical geography of the islands which was not assessed in my research was land type. The islands in the archipelago represent a diverse geological history. These range from volcanic islands, such as White Island, to remnants of volcanic rock, such as the Poor Knights Islands, to true oceanic islands (McSaveney, 2013). It is very possible that different geological groups will contain different species compositions. This was not a direction I wanted to take in my research however spatial maps which include land type information do exist for future research on the archipelago.

A different physical characteristic of islands purported to influence species richness is elevation. In studies concerning total species richness it has been reported that the richness-elevation relationship has most often been linear and negative or hump-shaped (M. W. Denslow, Palmer, \& Murrell, 2010). There have also been studies, although very few, that have assessed the different responses of exotic and native richness towards an elevation gradient. In a study comparing exotic to native richness Palmer, Pyšek, Kaplan, and Richardson (2006) found that elevation similarly influenced both exotics and native species. On the other hand M. W. Denslow et al. (2010) only found the expected hump-shaped relationship in native species. Elevation records for the islands in my study site were only obtainable for around 100 of the islands and as such could not be quantitatively assessed without making large assumptions. The islands with missing elevation data were most often very small islands. Therefore running the GLM on just the 100 islands with known elevations would have excluded a non-random sample of small islands. Alternatively, a maximum elevation such as $10 \mathrm{~m}$ could have been estimated for the other islands. However, given that this was almost half of the islands this would have misconstrued the dataset altogether. In future 
studies the use of topographical maps and GIS may allow the calculation of island elevations on the archipelago. If the elevation of more of the islands can be obtained then this database could produce a rare comparison of the species-elevation relationship between exotic and native species

The nature of exotic species is that human activity has aided their immigration into new geographical areas (Hulme, 2009). The role of human impact, which was not quantitatively assessed here, could be an underlying factor shaping the observed richness patterns. It could be suggested for example that the nearer islands in the archipelago have had more human impact as they are more accessible. Exotic species are commonly spread by anthropogenic movement and so this might explain the higher proportion of exotic richness on nearer islands. The majority of islands in the study have recorded human contact since the 1900's (McSaveney, 2013) however it is difficult to measure the degree of human impact as a metric (Blackburn et al., 2015; Kueffer et al., 2010). Thus in future analyses of this database quantitatively assessing human impact could be an informative approach.

\subsection{Conservation management}

The Hawaiki archipelago was a model laboratory to test the differences between native and exotic plant richness. This species dichotomy is important given the threat of certain exotic species to global species diversity. The management of invasive species has drawn considerable economic resources. One earlier study quantified the effects of invasive species in the U.S. to be $\$ 120$ billion annually (Pimentel et al., 2005) whilst Vitousek (1977) cite invasive as one of the world's worst environmental threats.

In New Zealand we have been fortunate because the continued arrival of exotic species has not coincided with the loss of native plant species as reported in other parts of the world (Hulme, 2009; Sax et al., 2002). Efforts to control the spread of exotic plant species in New Zealand include 
weeding programmes organised by the Department of Conservation (DOC). The current weeding effort in the study area has existed for at least 20 years (Atkinson, 1997).The key result from my research on the archipelago in terms of conservation was the decreasing percentage of exotic plant species with increasing distance from the mainland. Furthermore the size of the island was the single most significant indicator of exotic richness. The implications for conservation management on the Hawaiki archipelago are thus that weeding efforts should focus on larger islands and particularly those closer to the mainland. Implications from this research are also of direct use for other weed control programmes on New Zealand islands as well as abroad.

\subsection{General conclusion}

During the last two centuries the global composition of species has altered dramatically due to the anthropogenic spread of exotic species (Clavero \& Garcia-Berthou, 2005; Pimentel et al., 2005). The general significance of exotic species to local diversity is still uncertain however one of the ecological patterns often used to examine this is the species-area relationship. The ultimate goal for such research is to accurately predict any future loss of diversity. If native species are at risk then the challenge is then to create applications in conservation management for prevention. My research and the few other similar studies suggest that the species-isolation relationship could also hold key insights into the future patterns of exotic species. Crucially, I found that exotic species were more influenced by isolation from the mainland than native species and I consequently suggest that the management programme by DOC focuses on islands near the mainland. Beyond the Hawaiki archipelago it may be possible that the results are also applicable on a global scale. However, only future studies of a similar nature will allow us to know whether these results are indicative of a greater general pattern. Were these trends to be general in nature they could be used to better inform more effective and efficient management efforts both in NZ and abroad. 


\section{References}

Atkinson, I. (1997). Problem weeds on New Zealand islands.

Blackburn, T. M., Delean, S., Pyšek, P., \& Cassey, P. (2015). On the island biogeography of aliens: a global analysis of the richness of plant and bird species on oceanic islands. Global Ecology and Biogeography.

Blackburn, T. M., Pyšek, P., Bacher, S., Carlton, J. T., Duncan, R. P., Jarošík, V., . . Richardson, D. M. (2011). A proposed unified framework for biological invasions. Trends in Ecology \& Evolution, 26(7), 333-339.

Brooks, W. R., Lockwood, J. L., \& Jordan, R. C. (2013). Tropical paradox: a multi-scale analysis of the invasion paradox within Miami Rock Ridge tropical hardwood hammocks. Biological invasions, 15(4), 921-930.

Brown, J., \& Sax, D. (2004). Gradients in species diversity: why are there so many species in the tropics. Foundations of Biogeography: Classic Papers with Commentaries, 1145-1154.

Burns, K. C. (2015). A Theory of Island Biogeography for Exotic Species. The American Naturalist, 186(4), 441.

Clark, G. F., \& Johnston, E. L. (2011). Temporal change in the diversity-invasibility relationship in the presence of a disturbance regime. Ecology Letters, 14(1), 52-57.

Clark, G. F., Johnston, E. L., \& Leung, B. (2013). Intrinsic time dependence in the diversity-invasibility relationship. Ecology, 94(1), 25-31.

Clavero, M., \& Garcia-Berthou, E. (2005). Invasive species are a leading cause of animal extinctions. TRENDS in Ecology and Evolution, 20(3), 110-110.

Crawley, M. J. (1987). What makes a community invasible? Colonization, succession and stability. 26th BES symposium, 429-453. Retrieved from http://www.scopus.com/inward/record.url?eid=2-s2.0-

0023527592\& partner ID $=40 \& m d 5=90$ be8e31bce270bdd7803aa83c0c6315

Daehler, C. C. (2003). Performance comparisons of co-occurring native and alien invasive plants: implications for conservation and restoration. Annual Review of Ecology, Evolution, and Systematics, 183-211.

Darlington, P. J. (1957). Zoogeography.

Davis, M. A. (2009). Invasion biology: Oxford University Press on Demand.

Davis, M. A., Chew, M. K., Hobbs, R. J., Lugo, A. E., Ewel, J. J., Vermeij, G. J., . . Carroll, S. P. (2011). Don't judge species on their origins. Nature, 474(7350), 153-154.

Denslow, J. S. (2003). Weeds in paradise: thoughts on the invasibility of tropical islands. Annals of the Missouri Botanical Garden, 119-127.

Denslow, M. W., Palmer, M. W., \& Murrell, Z. E. (2010). Patterns of native and exotic vascular plant richness along an elevational gradient from sea level to the summit of the Appalachian Mountains, USA. The Journal of the Torrey Botanical Society, 137(1), 67-80.

DeWalt, S. J., Denslow, J. S., \& Ickes, K. (2004). Natural-enemy release facilitates habitat expansion of the invasive tropical shrub Clidemia hirta. Ecology, 85(2), 471-483.

Diamond, J. M. (1975). The island dilemma: lessons of modern biogeographic studies for the design of natural reserves. Biological conservation, 7(2), 129-146.

Diver, K. C. (2008). Not as the crow flies: assessing effective isolation for island biogeographical analysis. Journal of Biogeography, 35(6), 1040-1048.

Elton, C. S. (1958). The ecology of invasions by animals and plants. London, UK: Methuen.

Environmental Systems Research Institute (ESRI), (2014). ArcGIS Desktop Help 10.2 Geostatistical Analyst. http://resources.arcgis.com/en/help/main/10.2/index.html

Fridley, J., Stachowicz, J., Naeem, S., Sax, D., Seabloom, E., Smith, M., . . Holle, B. V. (2007). The invasion paradox: reconciling pattern and process in species invasions. Ecology, 88(1), 3-17.

Gilpin, M. E. (1980). The role of stepping-stone islands. Theoretical population biology, 17(2), 247253. 
Grason, E. (2014). Retrieved from www.biodiverseperspectives.com/2014/04/22/no-forest-is-anisland-except-maybe-the-ones-that-are/

Guo, Q. (2015). No consistent small-scale native-exotic relationships. Plant Ecology, 216(9), 12251230.

Hubbell, S. P. (2001). The unified neutral theory of biodiversity and biogeography (MPB-32) (Vol. 32): Princeton University Press.

Hulme, P. E. (2009). Trade, transport and trouble: managing invasive species pathways in an era of globalization. Journal of Applied Ecology, 46(1), 10-18.

IBM Corp. Released 2013. IBM SPSS Statistics for Windows, Version 22.0. Armonk, NY: IBM Corp

Kennedy, T. A., Naeem, S., Howe, K. M., Knops, J. M., Tilman, D., \& Reich, P. (2002). Biodiversity as a barrier to ecological invasion. Nature, 417(6889), 636-638.

Knight, K. S., \& Reich, P. B. (2005). Opposite relationships between invasibility and native species richness at patch versus landscape scales. Oikos, 109(1), 81-88.

Kreft, H., Jetz, W., Mutke, J., Kier, G., \& Barthlott, W. (2008). Global diversity of island floras from a macroecological perspective. Ecology Letters, 11(2), 116-127.

Kueffer, C., Daehler, C. C., Torres-Santana, C. W., Lavergne, C., Meyer, J.-Y., Otto, R., \& Silva, L. (2010). A global comparison of plant invasions on oceanic islands. Perspectives in Plant Ecology, Evolution and Systematics, 12(2), 145-161.

Lack, D. (1970). Island birds. Biotropica, 29-31.

Laurance, W. F. (2008). Theory meets reality: how habitat fragmentation research has transcended island biogeographic theory. Biological conservation, 141(7), 1731-1744.

Levine, J. M., \& D'Antonio, C. M. (1999). Elton revisited: a review of evidence linking diversity and invasibility. Oikos, 15-26.

LINZ. NZ Coastlines (Topo, 1:50k). Retrieved from https://data.linz.govt.nz/layer/258-nz-coastlinestopo-150k/

LINZ. NZ Island Polygons (Topo, 1:50k). Retrieved from https://data.linz.govt.nz/layer/288-nzisland-polygons-topo-150k/

Lomolino, M. V., \& Brown, J. H. (2009). The reticulating phylogeny of island biogeography theory. The Quarterly review of biology, 84(4), 357.

Lomolino, M. V., Brown, J. H., \& Davis, R. (1989). Island biogeograhy of montane forest mammals in the American Southwest. Ecology, 180-194.

Lomolino, M. V., Brown, J. H., \& Sax, D. F. (2010). Island biogeography theory. The theory of island biogeography revisited, 13.

Long, J. D., Trussell, G. C., \& Elliman, T. (2009). Linking invasions and biogeography: isolation differentially affects exotic and native plant diversity. Ecology, 90(4), 863-868.

Losos, J. B., \& Ricklefs, R. E. (2009). The theory of island biogeography revisited: Princeton University Press.

MacArthur, R. H., \& Wilson, E. O. (1963). An equilibrium theory of insular zoogeography. Evolution, 373-387.

Mackey, B., DellaSala, D. A., Kormos, C., Lindenmayer, D., Kumpel, N., Zimmerman, B., . . Arsenis, K. (2015). Policy options for the world's primary forests in multilateral environmental agreements. Conservation Letters, 8(2), 139-147.

McSaveney, E. (2013). Story: Nearshore islands. Retrieved from www.teara.govt.nz/en/nearshoreislands

Moody, A. (2000). Analysis of plant species diversity with respect to island characteristics on the Channel Islands, California. Journal of Biogeography, 27(3), 711-723.

Naeem, S., Knops, J. M., Tilman, D., Howe, K. M., Kennedy, T., \& Gale, S. (2000). Plant diversity increases resistance to invasion in the absence of covarying extrinsic factors. Oikos, 91(1), 97-108.

Palmer, M. W., Pyšek, P., Kaplan, Z., \& Richardson, D. (2006). Scale dependence of native and alien species richness in North American floras. Preslia, 78(4), 427-436. 
Pimentel, Morrison, \& Zuniga. (2005). Update on the environmental and economic costs associated with alien-invasive species in the United States. Ecological Economics.

Pyšek, P. (1998). Alien and native species in Central European urban floras: a quantitative comparison. Journal of Biogeography, 25(1), 155-163.

Quammen, D. (2012). The song of the dodo: island biogeography in an age of extinctions: Random House.

Rosenzweig, M. L. (1995). Species diversity in space and time: Cambridge University Press.

Sax, D. F., \& Gaines, S. D. (2006). Ther biogeography of naturalized species and the species-area relationship: reciprocal insights to biogeography ans invasion biology Conceptual ecology and invasion biology: reciprocal approaches to nature (pp. 449-480): Springer.

Sax, D. F., Gaines, S. D., \& Brown, J. H. (2002). Species invasions exceed extinctions on islands worldwide: a comparative study of plants and birds. The American Naturalist, 160(6), 766783.

Shea, K., \& Chesson, P. (2002). Community ecology theory as a framework for biological invasions. Trends in Ecology \& Evolution, 17(4), 170-176.

Simberloff, D. S., \& Abele, L. G. (1976). Island biogeography theory and conservation practice. Science, 191(4224), 285-286.

Stachowicz, J. J., Whitlatch, R. B., \& Osman, R. W. (1999). Species diversity and invasion resistance in a marine ecosystem. Science, 286(5444), 1577-1579.

Stohlgren, T. J., Barnett, D. T., \& Kartesz, J. T. (2003). The rich get richer: patterns of plant invasions in the United States. Frontiers in Ecology and the Environment, 1(1), 11-14.

Stohlgren, T. J., Jarnevich, C., Chong, G. W., Evangelista, P. H., Pyšek, P., Kaplan, Z., \& Richardson, D. (2006). Scale and plant invasions: a theory of biotic acceptance. Preslia, 78(4), 405-426.

Strayer, D. L., Eviner, V. T., Jeschke, J. M., \& Pace, M. L. (2006). Understanding the long-term effects of species invasions. Trends in Ecology \& Evolution, 21(11), 645-651.

Vitousek, P. M. (1977). The regulation of element concentrations in mountain streams in the northeastern United States. Ecological Monographs, 65-87.

Vitousek, P. M. (1990). Biological invasions and ecosystem processes: towards an integration of population biology and ecosystem studies Ecosystem Management (pp. 183-191): Springer.

Warren, B. H., Simberloff, D., Ricklefs, R. E., Aguilée, R., Condamine, F. L., Gravel, D., . . Casquet, J. (2015). Islands as model systems in ecology and evolution: prospects fifty years after MacArthur-Wilson. Ecology Letters, 18(2), 200-217.

Whittaker, R. J., \& Fernández-Palacios, J. M. (2007). Island biogeography: ecology, evolution, and conservation: Oxford University Press.

Whittaker, R. J., Triantis, K. A., \& Ladle, R. J. (2008). A general dynamic theory of oceanic island biogeography. Journal of Biogeography, 35(6), 977-994.

Wiens, J. A. (1996). Wildlife in patchy environments: metapopulations, mosaics, and management. Metapopulations and wildlife conservation. Island Press, Washington, DC, USA, 439, 53-84.

Wilson, E. O., \& MacArthur, R. H. (1967). The theory of island biogeography. Princeton, NJ. 